\title{
The burden of neglected tropical diseases in Ethiopia, and opportunities for integrated control and elimination
}

Kebede Deribe ${ }^{1 *}$, Kadu Meribo $^{2}$, Teshome Gebre ${ }^{3}$, Asrat Hailu $^{4}$, Ahmed Ali ${ }^{5}$, Abraham Aseffa $^{6}$ and Gail Davey ${ }^{1}$

\begin{abstract}
Background: Neglected tropical diseases (NTDs) are a group of chronic parasitic diseases and related conditions that are the most common diseases among the 2.7 billion people globally living on less than US\$2 per day. In response to the growing challenge of NTDs, Ethiopia is preparing to launch a NTD Master Plan. The purpose of this review is to underscore the burden of NTDs in Ethiopia, highlight the state of current interventions, and suggest ways forward.
\end{abstract}

Results: This review indicates that NTDs are significant public health problems in Ethiopia. From the analysis reported here, Ethiopia stands out for having the largest number of NTD cases following Nigeria and the Democratic Republic of Congo. Ethiopia is estimated to have the highest burden of trachoma, podoconiosis and cutaneous leishmaniasis in sub-Saharan Africa (SSA), the second highest burden in terms of ascariasis, leprosy and visceral leishmaniasis, and the third highest burden of hookworm. Infections such as schistosomiasis, trichuriasis, lymphatic filariasis and rabies are also common. A third of Ethiopians are infected with ascariasis, one quarter is infected with trichuriasis and one in eight Ethiopians lives with hookworm or is infected with trachoma. However, despite these high burdens of infection, the control of most NTDs in Ethiopia is in its infancy. In terms of NTD control achievements, Ethiopia reached the leprosy elimination target of 1 case/10,000 population in 1999. No cases of human African trypanosomiasis have been reported since 1984. Guinea worm eradication is in its final phase. The Onchocerciasis Control Program has been making steady progress since 2001. A national blindness survey was conducted in 2006 and the trachoma program has kicked off in some regions. Lymphatic Filariasis, podoconiosis and rabies mapping are underway.

Conclusion: Ethiopia bears a significant burden of NTDs compared to other SSA countries. To achieve success in integrated control of NTDs, integrated mapping, rapid scale up of interventions and operational research into co implementation of intervention packages will be crucial.

Keywords: Names of WHO listed neglected tropical disease, Integration, Elimination, Ethiopia

\section{Review}

Background

The Neglected Tropical Diseases (NTDs) are a group of chronic parasitic diseases and related conditions that represent the most common illnesses of the world's poorest people [1]. These diseases are the most common diseases of the 2.7 billion people globally who live on less than US\$2 per day [2]. More than 1 billion people -

\footnotetext{
* Correspondence: Kebededeka@yahoo.com

'Brighton and Sussex Medical School, Falmer, Brighton, United Kingdom Full list of author information is available at the end of the article
}

a seventh of the world's population - suffer from one or more Neglected Tropical Diseases [3]. Despite the substantial disease burden they impose, NTDs have largely been ignored in the global health architecture until recently. Social stigma, prejudice, marginalization and the extreme poverty of afflicted populations are among the factors contributing to the neglect of these diseases. Lack of funding for the prevention and treatment of these diseases is also a contributing factor [4].

Of more than seventeen NTDs, seven attract most attention because of their high prevalence and amenability to control worldwide [5]. These are the soil-transmitted 
helminth infections (hookworm, ascariasis, and trichuriasis); lymphatic filariasis; schistosomiasis; trachoma and onchocerciasis [5]. Globally, 600-800 million people have soil-transmitted helminth infections [5], 200 million people are infected with schistosomiasis, and 120 million with lymphatic filariasis in 83 countries $[5,6]$. Onchocerciasis affects nearly 37 million people in 34 countries, and is most abundant in Africa, with small foci in southern and Central America [7], while trachoma affects 84 million people globally [4].

NTDs have tremendous health and development impacts. These diseases hinder economic development, cause chronic life-long disability, and impair childhood development in the poor and disenfranchised communities in which they are most prevalent. They reduce child survival, educational attainment and agricultural productivity, and result in significant treatment costs $[4,5,8,9]$.

In Ethiopia, most of the NTDs in the WHO list are present [10-25], except for probably dengue fever, Chagas disease and yaws. Although comprehensive, systematic and integrated responses are lacking, control programs for individual NTDs such as onchocerciasis and trachoma exist at national scale. Despite the huge burden of NTDs in Ethiopia, no comprehensive reviews have quantified the burden or distribution of these NTDs. This review was conducted to document the prevalence and burden of NTDs in Ethiopia.

We identified seminal articles published in peerreviewed journals [10-37] and reports that were pertinent to the control of NTDs, using consultations with experts on this subject, and search of the key databases, including PubMed, archives of Ethiopian national journals and the WHO's Weekly Epidemiological Record using as search terms the specific diseases listed as NTDs by the World Health Organization. The websites of central and regional governments and of international agencies were accessed for relevant reviews, guidelines, and databases. The exclusion and inclusion criteria for the papers were deliberately kept flexible. The scope of the review was increased on the basis of findings from the review of key papers and reports. Relevant published and unpublished technical documents were accessed for review. Senior experts in several NTDs were included to mediate between the information found in the literature and practical knowledge on the ground.

\section{Review of disease burden}

\section{Soil transmitted helminths}

As indicated in Table 1 in Ethiopia, hookworm is estimated to infect 11 million people, thus Ethiopia bears $5.6 \%$ of the hookworm burden in Sub Saharan Africa (SSA) and is the country with the third highest burden in SSA [10]. Most parts of Ethiopia are suitable for the transmission of STHs, except parts of Somali and Afar regions where the annual mean temperature is too high for transmission [11]. The national prevalence of hookworm is estimated at $16 \%$ [12]. The prevalence of hookworm among school age children in Ethiopia was reported to be $38 \%$ in Jimma [13,14], 26.8\% in Boloso Sore [15], 53\% in central Ethiopia [16], 20.6\% in Southwest Ethiopia [17], and 19\% in northwest Ethiopia [18]. There was no significant gender difference [17]. According to a study conducted in southwest Ethiopia, 92\% of the hookworm infections were due to N. americanus and $8 \%$ were due to A. duodenale. None of the cultures showed mixed infection (infection by two or more species) [13].

Ethiopia has the second highest burden of ascariasis in SSA: 26 million people are infected, which is $15 \%$ of the overall burden in SSA [10]. The prevalence among school age children was recorded at $28.9 \%$ in northern Ethiopia [33], 83.4\% in southern Ethiopia [34], 22\% in northwest Ethiopia [18], and the national average is estimated at 37\% [12]. Similarly, Ethiopia has the $4^{\text {th }}$ highest burden of Trichuriasis, with 21 million people infected, which is $13 \%$ of the disease burden in SSA [10]. The national prevalence is estimated at 30\% [12]. The global atlas of helminth infection (http://www.thiswormyworld. org/maps/ethiopia/archive) provides a predictive map of STH in Ethiopia.

\section{Schistosomiasis}

In Ethiopia, 5.01 million are thought to be infected with schistosomiasis and 37.5 million to be at risk [19]. The national schistosomiasis survey of 1988-89 reported an overall prevalence of $25 \%$ [35,36]. Among 365 communities surveyed for S. mansoni between 1961 and 1986, prevalence ranged from 10 to 92\% [37]. Transmission occurs mainly through streams, irrigation schemes, and lakes. The intensity of infection correlates with severity of infection, and varies from locality to locality in Ethiopia.

In some studies the prevalence of S.mansoni infection was higher in children and adolescents [36], because children had higher environmental contamination potential. Prevalence in males and in females was $42.4 \%$ and $26.5 \%$ respectively [35].

\section{Leishmaniasis}

Ethiopia is one of the six countries (Bangladesh, Brazil, Ethiopia, India, Nepal and Sudan) in which more than $90 \%$ of global Visceral Leishmaniasis (VL) cases occur and one of the ten countries with the highest estimated case counts, which together account for 70 to $75 \%$ of global estimated VL incidence [1]. Both Cutaneous Leishmaniasis (CL) and $\mathrm{VL}$ are growing health problems in Ethiopia, with endemic areas that are continually spreading. Geographically, VL is found in Tigray, Amhara, Oromia, Afar, Somali and SNNPR, whereas CL is prevalent in Tigray, Amhara, SNNPR, Addis Ababa and Oromia regions. 
Table 1 Summary of burden of neglected tropical disease in Ethiopia, 2012

\begin{tabular}{|c|c|c|c|}
\hline Disease & Geographical distribution & Burden of disease in Ethiopia & $\begin{array}{l}\text { Proportion of SSA } \\
\text { prevalence [10] }\end{array}$ \\
\hline Hookworm infection & Most of Ethiopia is suitable for transmission & 11 million [10] & $29 \%$ \\
\hline Ascariasis & Most of Ethiopia is suitable for transmission & 26 million [10] & $25 \%$ \\
\hline Trichuriasis & Most of Ethiopia is suitable for transmission & 21 million [10] & $24 \%$ \\
\hline Schistosomiasis & Most of Ethiopia is suitable for transmission & 5.01 million [19], 37.5 million at risk & $25 \%$ \\
\hline Lymphatic filariasis & $\begin{array}{l}\text { Gambella (7), Beneshangul-Gumuz (13), SNNPR (9), } \\
\text { Amhara (2) and Oromia (3) endemic districts. [20] }\end{array}$ & 30 million at risk [10] & $6 \%-9 \%$ \\
\hline Onchocerciasis & $\begin{array}{l}\text { Amhara Region (North Gondar), Benishangul-Gumuz } \\
\text { (Metekel Zone), Oromia (Jimma, llubabor, Wellega, } \\
\text { West Shoa), SNNPR (Kaffa, Sheka and Bench Maji Zone) } \\
\text { and Gambella. }\end{array}$ & 5 million cases and 12 million at risk [12] & $5 \%$ \\
\hline Podoconiosis & One fifth of the surface of Ethiopia & 1 million cases, 19.2 million at risk $[21,22]$ & \\
\hline Trachoma & $\begin{array}{l}\text { Trachoma is found in all regions of Ethiopia. } \\
\text { Six regions - Amhara, Oromia, SNNPR, Tigray, } \\
\text { Somali and Gambella - bear high burden. }\end{array}$ & $\begin{array}{l}\text { Ethiopia } 10.3 \text { million active trachoma, } \\
1.3 \text { million TT cases, [23], > } 65 \text { million at risk }\end{array}$ & $3 \%$ \\
\hline $\begin{array}{l}\text { Human African } \\
\text { trypanosomiasis }\end{array}$ & Historically Gambella and South Omo (SNNPR) & No cases of HAT since 1984 [24] & $<0.01 \%$ \\
\hline Leprosy & $\begin{array}{l}\text { Leprosy has been reported from most part of the } \\
\text { country except part of Afar and Somali region. }\end{array}$ & 4,611 new cases per annum [25] & $<0.01 \%$ \\
\hline Leishmaniasis & $\begin{array}{l}\text { VL is found in Tigray, Amhara, Oromia, Somali, } \\
\text { Afar and SNNPR, whereas CL is prevalent in Tigray, } \\
\text { Amhara, Addis Ababa, SNNPR, and Oromia. }\end{array}$ & $\begin{array}{l}4,000 \text { new cases of } V L \text { per annum [26] } \\
20-50,000 \text { cases of } C L \text { per annum [26] }\end{array}$ & $<0.01 \%$ \\
\hline Dracunculiasis & Gambella Region and historically South Omo (SNNPR) & 8 cases in 2011 [27] & $<0.01 \%$ \\
\hline Buruli ulcer & $\begin{array}{l}\text { Two case reported from Arbaminch Zuria district } \\
\text { (SNNPR) and Tigray regions }\end{array}$ & 2 cases reported $[28,29]$ & $<0.01 \%$ \\
\hline Echinococcosis & Unknown & $1817(2.3 / 100,000)$ per annum [30] & Unknown \\
\hline Rabies & Most part of the country & $\begin{array}{l}\text { 996-14694(12.6/million-18.6/100,000) } \\
\text { per annum }[31,32]\end{array}$ & Unknown \\
\hline Fascioliasis & Unknown & Unknown & Unknown \\
\hline
\end{tabular}

Historically the first case of VL in Ethiopia was identified in 1942 in southern Ethiopia. Every year, an estimated 3700-7400 cases occur in Ethiopia (Figure 1) [38]. The disease occurs in the lowlands of the northwest, central, south and southwestern parts of the country. In the north, the

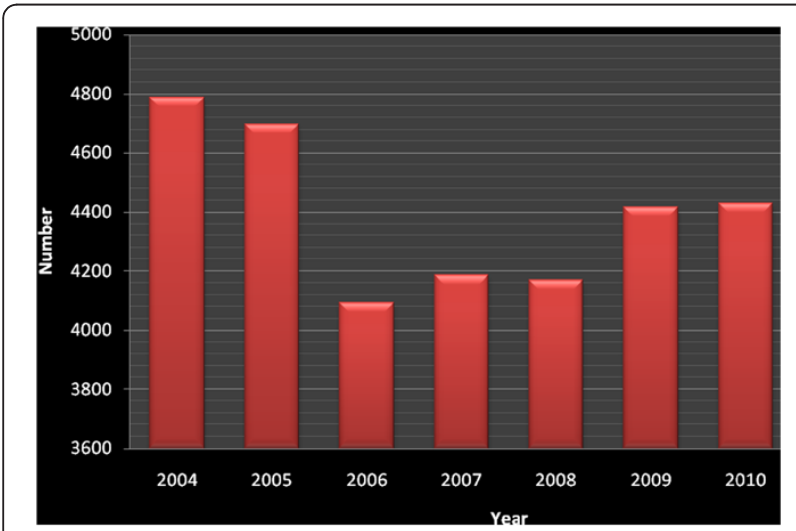

Figure 1 Cases of Visceral Leishmaniasis, Ethiopia, 2004-2010 [26]. vector is associated with Acacia-Balanites forest, in the south with termite hills. In Ethiopia, VL affects mainly children and young adults (the mean age of affected in northern Ethiopia is 23) in endemic areas the mean age is much lower [26,38]. In northwest Ethiopia, where migrant laborers are at risk of exposure to VL, annual incidence ranges from 5 to 8 cases per 1000 . The annual incidence among at risk populations in southern and south eastern Ethiopia ranges from 1 to 5 per thousand with huge geographical variation (AH unpublished observations).

CL has been well known since 1913, and is endemic in most regions, mainly in the highlands of Ethiopia in the altitude ranges of $1400-2900 \mathrm{~m}$. It is a highly neglected disease with a zoonotic cycle involving rock hyraxes. There are estimated $20-50,000$ cases yearly, but only 450 cases were reported in 2008 [26]. There are three clinical forms of CL in Ethiopia: localized CL, mucosal leishmaniasis and diffuse cutaneous leishmaniasis (DCL), all mainly caused by $L$. aethiopica. CL is most common in children $[39,40]$. In highly endemic areas, children less than 10 are affected, for example $8.5 \%$ of under 10 s in Ochollo, southwestern Ethiopia [41]. The prevalence of CL in the vast majority of 
the endemic areas varies from $0.1 \%$ to $1.0 \%$ (AH unpublished observations); and higher prevalence rates were reported in hyperendemic areas, e.g. 3.6-4.0\% in Ochollo [41], and 4.8\% in Silti Woreda [42].

Outbreaks of leishmaniasis have occurred in Ethiopia. Between 2005-2008, a documented outbreak of VL occurred in Amhara Region (Libo Kemkem), with 2,500 cases and with a very high mortality [43,44]. An outbreak of CL occurred in Silti district 2003-2005 [45]. In 2010, cases of VL were identified in Tigray (Tahtay Adiabo district) and East lmey, a district in Somali region [38]. The incidence of HIV-Leishmania co-infection is very high (23\% in 2008$)$ in north Ethiopia $[46,47]$.

\section{Lymphatic filariasis}

Lymphatic filariasis (LF) is a parasitic disease of man caused by three species of filarial parasites: Wuchereria bancrofti, Brugia malayi and B. timori, which are transmitted by anopheline and culicine mosquitoes $[6,48,49]$. LF is one of the most debilitating and disfiguring diseases in Ethiopia and is caused by W. bancrofti. The adult worms inhabit the lymphatics, and may lead to lymphoedema and elephantiasis. The disease is poverty-related and predominantly affects the poor and marginalized people [20,49]. In Ethiopia, 30 million people have been estimated to be at risk of LF, which would make Ethiopia the $4^{\text {th }}$ highest burden country in SSA, bearing $7.8 \%$ of the burden of LF in SSA (Table 2). However, some experts question the validity of this estimate, considering it to be an overestimation compared to recent surveys. The on-going mapping activities are intended to provide a realistic figure about the numbers of people at risk.

According to recent mapping based on 11,685 individuals living in 125 villages (112 districts) of western Ethiopia, the prevalence was $3.7 \%$, but high geographical clustering and variation in prevalence (ranging from $0 \%$ to more than $50 \%$ ) was found. The prevalence of hydrocele (in males) and limb lymphoedema was $0.8 \%$ and $3.6 \%$, respectively. Endemic districts were identified in the following regions: Gambella Region (seven districts), Beneshangul-Gumuz Region (thirteen districts), and Southern Nations, Nationalities and Peoples' Region (SNNPR) (nine districts). The other five districts were from Amhara (two districts) and Oromia (three districts) regions [20].

\section{Podoconiosis}

Podoconiosis (endemic non-filarial elephantiasis) is a non-infectious geochemical disease caused by exposure

Table 2 Burden of neglected tropical disease in Ethiopia and relative contribution and rank within Sub-Saharan Africa, 2012

\begin{tabular}{|c|c|c|c|c|}
\hline Disease & Ethiopia & SSA [10] & $\begin{array}{l}\text { Percentage contribution } \\
\text { of Ethiopia to SSA }\end{array}$ & Disease burden rank from SSA \\
\hline Hookworm infection & 11 million [10] & 198million & $5.6 \%$ & 3 \\
\hline Ascariasis & 26 million [10] & 173 million & $15.0 \%$ & 2 \\
\hline Trichuriasis & 21 million [10] & 162 million & $13.0 \%$ & 4 \\
\hline Schistosomiasis & 5.01 million [19] & 192 million & $2.6 \%$ & 14 \\
\hline Lymphatic filariasis & $\begin{array}{l}\text { Ethiopia } 30 \text { million } \\
\text { at risk [10] }\end{array}$ & 382-394 million at risk & $7.6 \%-7.8 \%$ & 4 \\
\hline Onchocerciasis & $\begin{array}{l}5 \text { milion, } 12 \text { million } \\
\text { at risk [12] }\end{array}$ & 37 million & $8.1 \%$ & $\begin{array}{l}\text { Using annual treatment figures provided } \\
\text { by APOC in } 2010 \text { as proxy indicators, } \\
\text { Ethiopia stands } 4 \text { th following Nigeria, } \\
\text { DRC and Cameroon. }\end{array}$ \\
\hline Podoconiosis & $\begin{array}{l}1 \text { million cases, } 19.2 \text { million } \\
\text { at risk }[21,22]\end{array}$ & 4 million & $25 \%$ & 1 \\
\hline Trachoma & Ethiopia 10.3 million $[10,23]$ & 30 million & $34.3 \%$ & 1 \\
\hline $\begin{array}{l}\text { Human African } \\
\text { trypanosomiasis }\end{array}$ & 0 since 1984 [24] & $50,000-70,000$ & 0 & \\
\hline Leprosy & Ethiopia 4,611 annual [25] & 30,055 & $15.3 \%$ & 2 \\
\hline Leishmaniasis & $\begin{array}{l}\text { Ethiopia } 4,000 \text { new Cases } \\
\text { annual [26] }\end{array}$ & $19,000-24,000$ & $16.7 \%-21.1 \%$ & 2 \\
\hline Dracunculiasis & 8 cases in 2011 [27] & 1058 & $0.75 \%$ & 4 \\
\hline Buruli ulcer & 2 cases $[28,29]$ & $>4,000$ & Unknown & Unknown \\
\hline Fascioliasis & Few cases reported & Unknown & Unknown & Unknown \\
\hline Echinococcosis & 1,817annual [30] & Unknown & Unknown & Unknown \\
\hline Rabies & 996-14694 annual $[31,32]$ & Unknown & Unknown & Unknown \\
\hline
\end{tabular}


of bare feet to red clay soil derived from volcanic rocks. Ethiopia is estimated to bear one fourth $(25 \%)$ of the global burden of podoconiosis, with up to 1 million cases of podoconiosis existing in Ethiopia [21,22,50]. The disease occurs in highland red clay soil areas, mainly among poor, barefoot agricultural communities, who do not wear protective shoes. In endemic areas of Ethiopia, the prevalence of podoconiosis is high - 9.1\% in Illubabor Zone, Oromia Region [51]. The socioeconomic impact of the disease is high: of 10 patients, seven to nine tend to belong to the economically active age group population, and podoconiosis is estimated to result in a loss of USD 1.6 million per year in one zone of 1.6 million people alone, suggesting that at national level, the economic losses due to podoconiosis may be higher than USD 200 million per year [22]. Podoconiosis is also one of the most stigmatizing diseases in endemic areas. The disease leads to social exclusion of individuals and their families [52].

\section{Trachoma}

Trachoma, caused by Chlamydia trachomatis (an obligate intracellular bacterium), is the leading infectious cause of blindness worldwide [53].

The national blindness, low vision and trachoma survey conducted in Ethiopia in 2005/6 suggests that Ethiopia is the most trachoma-affected country in the world. The entire rural population of approximately 65 million people is at risk of blinding trachoma. It was estimated that in 2008, there were 9.84 million children with clinical signs of active disease and 1.36 million adults with trachomatous trichiasis. In the same study, projections suggested that in 2008 a total of 1,143,151 people were blind from avoidable causes, of which trachoma accounted for $11.5 \%$. Provided appropriate interventions are in place, about $90 \%$ of all blindness in the country is avoidable [23,54]. The prevalence of blindness in Ethiopia is thought to be the highest in the world. After cataract, the preventable bacterial infection trachoma was the secondleading cause of blindness in Ethiopia. There are 10 million individuals with active trachoma in the country placing the vast majority of the population at risk. The prevalence of active trachoma was $40.1 \%$ among children 1-9 years old [54,55]. Ethiopia ranks first in the list of high burden SSA countries and bears 34.5\% of the trachoma burden in the region. Ethiopia is one of the five countries including Guinea, India, Nigeria and Sudan bearing half of the global burden of active trachoma [1].

Trachoma is widely distributed in Ethiopia, with six regions bearing high burdens namely Amhara, Oromia, SNNPR, Tigray, Somali and Gambella regions [55].

\section{Onchocerciasis}

Onchocerciasis, also known as river blindness, is caused by a nematode filarial worm, Onchocerca volvulus that causes blindness and debilitating skin lesions [56].

The existence of onchocerciasis in Ethiopia has been known since 1939 as a result of investigation by Italians in south-western Ethiopia [57]. In Ethiopia, 5 million are estimated to be infected, with a further 12 million at risk from this disease $[12,58,59]$. The recent REMO mapping activity estimated that 5.2 million people are living in hyper- or meso-endemic areas [60]. Prevalence of onchocerciasis varies from place to place, from $84 \%$ in western endemic areas [61], to $19.5 \%$ in the northwest [19].

Onchocerciasis in Ethiopia is confined to the western part of the country, despite the presence of the vector in the other parts of the country. APOC-sponsored, nation-wide Rapid Epidemiological Mapping of Onchocerciasis (REMO) was first conducted in 1998. As a result, onchocerciasis was found to be prevalent in the North Gondar zone (Amhara Region), in Metekel and Assosa zones (Benishangul Region), Agnua and Mezhenger zones (Gambella region), in Illubabor, Jimma, East and West Welega zones (Oromia region), and in north Omo, South Omo, Kaffa Sheka and Bench-Maji zones (SNNPR [61]. In 1999 the National Onchocerciasis Control Program was established. The National Onchocerciasis Task Force (NOTF) was established in 2000 and the first CDTI project was launched in Kaffa-Sheka Zone in the same year. REMO refinement surveys were conducted in 2001, 2004 and 2011 [62].

\section{Leprosy}

In 2010, Ethiopia was one of the 17 countries reporting 1000 or more new cases per annum. Between 2004 and 2010, 4000-4500 new cases were diagnosed at health facilities annually. Ethiopia is the second highest burden country in SSA, after the Democratic Republic of Congo $[25,63]$. However, according to WHO, Ethiopia reached the leprosy elimination target of 1 case/10,000 population in 1999, and since then, the incidence has not changed appreciably [64]. As in other endemic countries, about 5,000 new cases are detected yearly and over 30,000 people are living with permanent leprosy-related disability. In 2002, clusters of endemicity with prevalence rates higher than the elimination target were recorded in four of the 14 administrative regions in the country [64]. In 2010, the total number of leprosy patients registered in the country was 5,303 , and of these, 4,430 were new cases. Of the registered new cases, 1,308 were female and 331 children. In the same year, 357 relapse cases were registered [63].

Ethiopia ranked 7th among the 18 countries that report $93 \%$ of all new cases detected globally in 2009, although prevalence dropped from 5081 to 4516, the average number of new cases remained constant at around a mean of 4524 (range 4153-4940) between 
2001-2011 (Figure 2). This translated to a drop in national case notification rate of $0.8 / 10,000$ to $0.6 / 10,000$. A $7.8 \%$ proportion of children under 15 and prevalence of $9.8 \%$ grade II disability rate among those newly diagnosed suggests an unknown magnitude of hidden cases. Regional variation in case notification rate varied between $0.16 / 10,000$ in SNNPR (which nevertheless had a grade II disability rate of $45 \%$ ) to $0.76 / 10,000$ in Oromia [65].

\section{Rabies}

Rabies is an important neglected zoonotic disease. Annually 996-14,694 cases of human rabies are estimated to occur in Ethiopia [31,32], mostly acquired through dog bites [66-68]. According to a study in and around Addis Ababa, 92\% of humans who received postexposure anti-rabies treatment had been bitten by dogs. In Africa, the highest recorded number of human deaths due to rabies for the year 1998 was 43, reported from Ethiopia [69]. Most cases of fatal rabies occur among children in Ethiopia [69]. Almost all of these deaths are preventable through prompt medical attention comprising wound cleaning and post-exposure prophylaxis with rabies vaccine. Often all had attempted some form of herbal remedies by traditional healers before presenting to health facilities [69]. There has been no apparent decline in the number of recorded human rabies cases over 20 years $[69,70]$.

\section{Dracunculiasis (guinea worm)}

Dracunculiasis is caused by the parasitic filarial worm Dracunculus medinensis, the largest of all the filarial worms (nematodes) affecting human [71,72]. Dracunculiasis used to be a formidable public health problem, mainly in terms of morbidity, incapacity and suffering of those affected. About $50 \%$ of cases suffer from secondary infections and become severely incapacitated [73].
In Ethiopia a case of dracunculiasis was reported first in 1969 [74]. Geographically, the disease was prevalent in Gambella region and South Omo (SNNPR). The eradication program in Ethiopia stated in 1990, and has reduced the number of cases from 1,252 in 1994 to only 8 in 2011 (Figure 3) $[27,75,76]$. Ethiopia is one of the four countries that reported dracunculiasis in 2011. The key challenge to achieving complete interruption of transmission is the very frequent migration and interaction of the people along the Ethio-Sudan border and very high likelihood of cross-border cases from South Sudan.

\section{Other NTDs in Ethiopia}

Human African trypanosomiasis has previously been reported in Ethiopia. The geographical distribution was in Gambella, with sporadic cases reported from Gamo Gofa, Keffa and Wellega. Since 1984 there have been no cases reported to WHO $[24,75,77]$.

Echinococcosis is a zoonotic disease caused by four species of Echinococcus: E. granulosus (causing cystic or unilocular echinococcosis); E. multilocularis, E. vogeli and $E$. oligarthrus (species causing polycystic or alveolar echinococcosis). In Ethiopia, humans become infected accidentally with E. granulosus through contact with dog's feces [75]. In a review of 36,402 patients admitted for ultrasound examination, an incidence of 2.3 cases per 100,000 per year was estimated [30].

Buruli ulcer is caused by infection with Mycobacterium ulcerans. In Ethiopia, only 2 cases were reported [28,29] from Arbaminch Zuria district. Ethiopia is not in the list of thirteen countries listed as endemic for Buruli ulcer in the African region.

\section{Current status of control and elimination of neglected tropical diseases in Ethiopia Onchocerciasis}

Although onchocerciasis was reported as early as 1939, part of the country was recognized to be endemic only in the

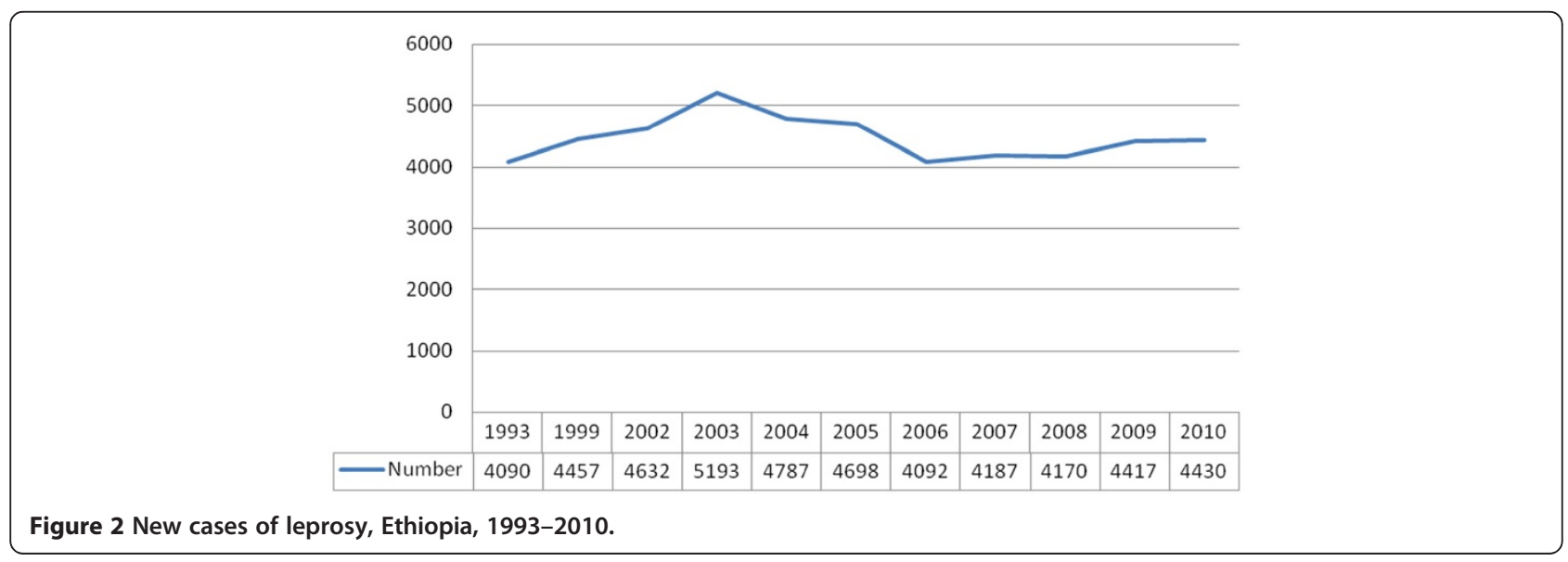




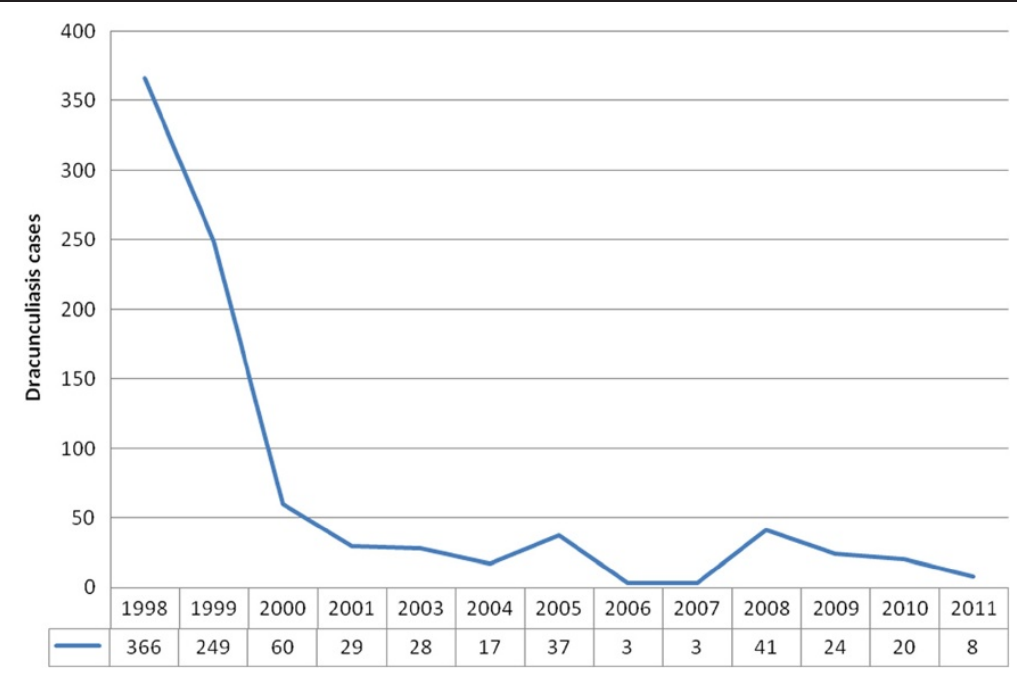

Figure 3 New cases of Dracunculiasis, Ethiopia, 1998-2011.

1970s [57]. The first national plan to fight onchocerciasis was developed in 1999. In 2000, the National Onchocerciasis Task Force was established by Ethiopia's Ministry of Health with a mission to: mobilize and educate onchocerciasis-endemic communities; coordinate Mecti$\mathrm{zan}^{\circledR}$ tablet procurement (donated by Merck) and distribution; and coordinate all partners in the program [57,62]. The Carter Center, Light for the World and the African Program for Onchocerciasis Control (APOC) play a critical role in supporting the Mectizan distribution program in these areas. The program went on to expand into other areas, doubling treatments each year until reaching scale in 2004. Treating more than 4 million annually, the program's geographic coverage reached $99.2 \%$ and sustained therapeutic coverage of $77.4 \%$ (Table 3) [60].

\section{Trachoma}

Ethiopia has a two-phase national five year Strategic Plan for eye care. Since 2000, Ethiopia has been implementing the World Health Organization-approved SAFE strategy for trachoma control - surgeries, antibiotics, face and hand washing and environmental hygiene. Through The Carter Center alone, using what is known as the MalTraWeek Strategy (combining malaria case detection and treatment with mass azithromycin distribution) more than 14.7 million people received azithromycin in 2010 [62]. In 2011, a total of 17.7 million people were treated with azithromycin in 195 districts. Over the past few years, annually about 60 - 90,000 cases of trichiasis have received TT surgery (FMOH, unpublished annual reports). Hygiene education and latrine promotion has been implemented nationwide through the health extension program. As a result, it was confirmed by DHS 2011 that individual latrine coverage (ownership and utilization) has reached $45 \%$ for rural households [78].

A number of clinical trials and pieces of operational research have been conducted over several years, to guide effective implementation of interventions for the eventual

Table 3 Onchocerciasis treatment in CDTI zones in 2010 in Ethiopia [62]

\begin{tabular}{llllll}
\hline CDTI Zone & $\begin{array}{l}\text { Ultimate treatment } \\
\text { goal }\end{array}$ & Total population & $\begin{array}{l}\text { Population } \\
\text { treated 2010 }\end{array}$ & $\begin{array}{l}\text { \% Ultimate } \\
\text { treatment goal }\end{array}$ & $\begin{array}{l}\text { Percent total } \\
\text { population treated }\end{array}$ \\
\hline Kaffa & 840,886 & 1001,055 & 784,716 & 93 & 78 \\
Sheka & 180,053 & 214,349 & 177,540 & 99 & 83 \\
Bench Maji & 579,848 & 690,295 & 543,038 & 94 & 79 \\
North Gondar & 238,369 & 283,773 & 215,632 & 90 & 76 \\
Illubabor & 648,750 & 772,321 & 639,544 & 99 & 83 \\
Jimma & 765,511 & 911,323 & 743,218 & 97 & 82 \\
Metekel & 127,079 & 151,284 & 121,072 & 95 & 80 \\
Gambella & 84,611 & 101,013 & 73,435 & 87 & 73 \\
Total & $3,465,107$ & $4,125,413$ & $3,298,195$ & 95 & 80 \\
\hline
\end{tabular}


control and elimination of trachoma in Ethiopia. A PubMed search indicated that a total of 86 trachoma research papers from Ethiopia have been published in local and international journals since 2001.

\section{Dracunculiasis}

The Ethiopian Ministry of Health established the National Dracunculiasis Eradication Program in 1993, and launched a village-by-village nationwide search during which 1,120 cases were found in 99 villages in the southwest part of the country $[57,75]$. Transmission of Guinea worm disease in the Southern Nations, Nationalities and Peoples Region (SNNPR) was interrupted in 2001 [75]. In 2007, Ethiopia reached a milestone by reporting zero indigenous cases for more than 12 consecutive months. Unfortunately, transmission of the disease resumed in 2008 when the country reported 41 indigenous cases [75]. The unexpected resurgence of Guinea worm disease in Gambella Region during 2008 demonstrates the constant need for vigilance in eradication efforts. Ethiopia reported 8 cases of dracunculiasis in 2011, including two cases imported from South Sudan [27]. In addition to the active case finding program, it is vital to enhance behavioral change and mobilize communities to prevent contamination of sources of drinking water. A cash reward system for case detection and reporting was found to be very helpful in facilitating effective surveillance and case containment activities.

\section{Lymphatic filariasis}

In 2009, with the support from The Carter Center, the Ethiopian Ministry of Health launched a LF elimination program in five districts of Gambella Region. The program reached $84 \%$ of its target by providing annual MDA of a single dose of ivermectin and albendazole to a target of almost 100,000 people. Recent LF mapping has identified new endemic districts in other regions indicating the need for expansion of the program to these places [20,62]. Integration must take into account both treatment goals and target group [79]. Currently there are other initiatives to establish sentinel sites and expand the treatment program.

\section{Podoconiosis}

Community-based lymphoedema management for podoconiosis was started in 1998 in Ethiopia by a nongovernment organization in Wolaita. The treatment appears to be effective, and patients show improvement after an average of three months treatment [79], though rigorous controlled assessment of this treatment is still necessary. The treatment includes foot hygiene, bandaging and elevation. Currently it is being run in three Regions of Ethiopia [80,81]. Although the implementation is still at small scale, it is attracting the attention of health care providers and health authorities for future possible integration into the national health system.

\section{Soil transmitted helminths}

Ethiopia launched an Enhanced Outreach Strategy (EOS) in 2004; one of the objectives of the initiative was to deworm 2-5 year old children every six months. The strategy was implemented in every district in the country except Addis Ababa and by 2009; the program had reached more than 11 million children in 624 districts. Every six months, with UNICEF support, Regional Health Bureaus organize the EOS. Each district has one EOS team per sub-district, composed of one health worker and one HEW who mobilize the community to come to the nearest health post on a specific day, the EOS day, when the EOS team deworms all children under five years and distributes vitamin A supplements. In many instances, the Regional Health Bureaus use this opportunity to deliver other essential services, such as measles vaccination, tetanus vaccination, mosquito net distribution, HIV/AIDS prevention, or iodine capsule distribution [82].

\section{Schistosomiasis}

Although Ethiopia is highly endemic for schistosomiasis, control of this disease is still in its infancy, and no recent mapping of schistosomiasis has taken place [83]. At a stakeholders meeting convened in July 2012 by the Schistosomiasis Control Initiative and the Ministry of Health, nationwide mapping of schistosomiasis integrated with mapping of other NTDs was planned for 2013, and strategies to expand MDA on the basis of the mapping outlined.

\section{Leishmaniasis}

In 2006, a leishmaniasis control program that included mandatory notification was established. Although patients are not required to pay for VL drugs and rK39 tests, other tests are not free of charge. It is estimated that treatment of VL patients usually requires a high cost to complete a full course of antimony-based treatments [26], and many are too poor to pay for these services. There are no vector control programs in place specifically for leishmaniasis, and bed net distribution and insecticide spraying take place in the context of malaria control [26,38,39]. A national Leishmaniasis control guideline has been developed. A geographic information system (GIS)-based risk mapping of leishmaniasis is being completed for the country and treatment guidelines for cutaneous leishmaniasis have been developed through an international consultation process organized by the $\mathrm{FMoH}$ in collaboration with the Armauer Hansen Research Institute (AHRI) and the World Health Organization (Proceedings available at AHRI). 


\section{Leprosy}

An organized leprosy control program was established within the Ministry of Health in 1956 with a detailed policy issued in 1969 operating as a vertical program. Multiple Drug Therapy (MDT) was implemented in 1983 leading to relatively rapid reduction in prevalence of leprosy. In 1994, leprosy was combined with tuberculosis under a joint control programme. By 2001, the leprosy component had been fully integrated into the general health services [65].

The FMoH is pursuing an Enhanced Global Strategy of integration with the general health service, reaching undeserved communities and effective partnership to reduce the rate of new cases with Grade II disabilities by at least $35 \%$ by the end of 2015 , compared to the baseline at the end of 2010 in line with the HSDP target of reducing Grade II disability to $1 \%$ by 2015 [65].

Ethiopia achieved the leprosy elimination target of 1 case/10,000 population in 1999 . The leprosy control program has been integrated with the tuberculosis control program within the national health system. Diagnosis and treatment services are provided free of charge for patients in every health center. In addition, rehabilitation services are provided for patients $[63,64]$. Early case detection remains a critical challenge. Specialized Leprosy expertise at the central level has been depleted over the last few years because of the shift of funding to tuberculosis and other diseases and resulting drift in brain flow.

\section{Other neglected tropical diseases}

In Ethiopia there have been no reported cases of HAT since 1984 [24]. No national program for control of rabies exists, although a national rabies survey is underway and there are sporadic initiatives to vaccinate dogs and provide post exposure vaccination free of charge. There is currently no detailed information about the extent of Buruli ulcer, echinococcosis and fascioliasis.

\section{Discussion}

This review indicates that Neglected Tropical Diseases are significant public health problems in Ethiopia. Compared to other countries in sub-Saharan Africa, Ethiopia bears a significant burden of many of these diseases. However, disease burden estimations are based on limited and often old data. From the analysis reported here, Ethiopia stands out as having the third largest total number of NTD cases following Nigeria and DRC. Ethiopia is estimated to have the highest burden of trachoma, podoconiosis and cutaneous leishmaniasis in SSA, the second highest burden of ascariasis, leprosy and visceral leishmaniasis, and the third highest burden of hookworm. Infections such as schistosomiasis, trichuriasis, LF and rabies are also common, yet despite these high burden infections, the control of most NTDs in Ethiopia is very limited.
Understanding which geographical areas require intervention is fundamental for cost-effective disease control $[79,84,85]$. Mapping of diseases should be preceded by review of existing data and followed by collection of data for those areas lacking this information. The most recent Rapid Epidemiological Mapping of Onchocerciasis identified new foci of transmission (meso and hyper endemic communities) that require mass treatment with Ivermectin [62], as well as areas to be refined before final decisions over inclusion or exclusion from treatment. Similarly, the western part of Ethiopia was mapped for Lymphatic Filariasis [20] and identified new transmission foci of LF beyond the previous altitude limits of transmission. Further mapping is therefore necessary to build a complete picture of the geographical distribution of LF in Ethiopia. Spatial analysis of a map compiling historical and recent data on podoconiosis distribution [86] indicated the presence of large scale spatial trends in the distribution of podoconiosis [Deribe K, Brooker SJ, Pullan RL, Davey G: Spatial distribution of Podoconiosis in Ethiopia: Results from historical maps and their implication on contemporary disease control; unpublished], but generated insufficient evidence to classify areas as endemic or non-endemic for podoconiosis. Collection of data for mapping of podoconiosis will improve understanding of the spatial distribution of podoconiosis and ecological factors determining this distribution. Experiences from Uganda $[79,87]$, Togo [88] and South Sudan [89] indicate the possibility of integrated disease mapping [90]. Togo and South Sudan conducted integrated mapping of STH, LF, trachoma, schistosomiasis, and onchocerciasis. These surveys were found to be cost-effective [89], with commendable epidemiological rigor. Such integrated disease mapping will have implications both in efficient resource utilization and integrated disease control. For example, integrated mapping of LF and podoconiosis is possible: the large scale autocorrelation of podoconiosis [Deribe $\mathrm{K}$, Brooker SJ, Pullan RL, Davey G: Spatial distribution of Podoconiosis in Ethiopia: Results from historical maps and their implication on contemporary disease control.; unpublished] suggests that sample sizes designed for LF will be more than adequate to capture the spatial distribution of podoconiosis. Second, diagnosis of LF needs exclusion of podoconiosis and vice versa, hence integrating the mapping of these two diseases will bring benefits in terms of reduced costs.

In Ethiopia, the nationwide blindness and trachoma prevalence survey conducted in 2006 [54] was followed by implementation of a five year strategic plan. To monitor the progress of this plan and identify areas that require further intervention, it will be necessary to update the trachoma map. Experience from Ethiopia has shown the feasibility of integrating trachoma surveys with malaria surveys, resulting in reduced costs, although some logistical challenges may arise [91]. 
It is not always mandatory to conduct surveys for mapping. Historical data modeled for environmental and demographic changes may be used for mapping the spatial distribution of disease and identifying populations at risk. For example in Kenya [92], historical and contemporary survey data were used to guide disease control. In Ethiopia many surveys have been conducted on soil-transmitted helminth (STH) infections and schistosomiasis [11,37], and these might be used to identify high risk areas for prioritization and generate maps for initiating interventions, as appropriate.

Traditional efforts to treat and prevent NTDs through vertical programs are often costly, and the integration of program components has the potential to cut the costs of NTD programs [93-97]. Because NTDs tend to overlap in geographic areas (Figure 4), it is logical to attempt an integrated approach to NTD control [93]. Since 2004, there has been greater advocacy for the integrated control of NTDs [94]. In Ethiopia there are geographical overlaps among NTDs, for example, according to the recent mapping of LF in Ethiopia [20], overlap between LF and onchocerciasis occurs in considerable geographical areas in the southwest of the country. Out of 34 LF endemic districts, 20 were also endemic for onchocerciasis. The existence of a well-established onchocerciasis control program in Ethiopia suggests that integration of other NTDs into this program might successfully build on the existing networks of community based drug distributors
(CDDs). In addition, a successful trachoma prevention and treatment program exists, into which MDA and deworming campaigns might be integrated. One practical example is the integration of trachoma services into the existing onchocerciasis control program through Community Drug Distributors in North Gondar. In most of the Community Directed Treatment with Ivermectin (CDTI) areas, the malaria program is integrated into the daily activities of CDDs. Malaria prevention activities are now included in the integrated CDD training course. CDDs are trained to record the number and condition of long lasting insecticidal nets (LLIN) [62]. Prevention efforts such as shoe wearing for podoconiosis may also help in prevention of chronic larva migrans and snakebite, so health promotion emphasizing the multiple benefits of shoe wearing may be valuable.

The high prevalence of HIV-leishmaniasis co-infection in Ethiopia $[45,46]$ brings an opportunity to integrate VL treatment and care with existing HIV treatment and care. While providing leishmaniasis patients with the option for HIV counseling and testing, screening of HIV positive individuals for leishmaniasis in endemic areas may avoid missed diagnoses. Hotez and colleagues [98] argue that the integration of NTD control may accelerate reductions in the prevalence or severity of HIV/AIDS, tuberculosis, and malaria.

Integration of NTD control into the existing health system is also another important issue. The integration of NTD control into the heath system will help ensure the

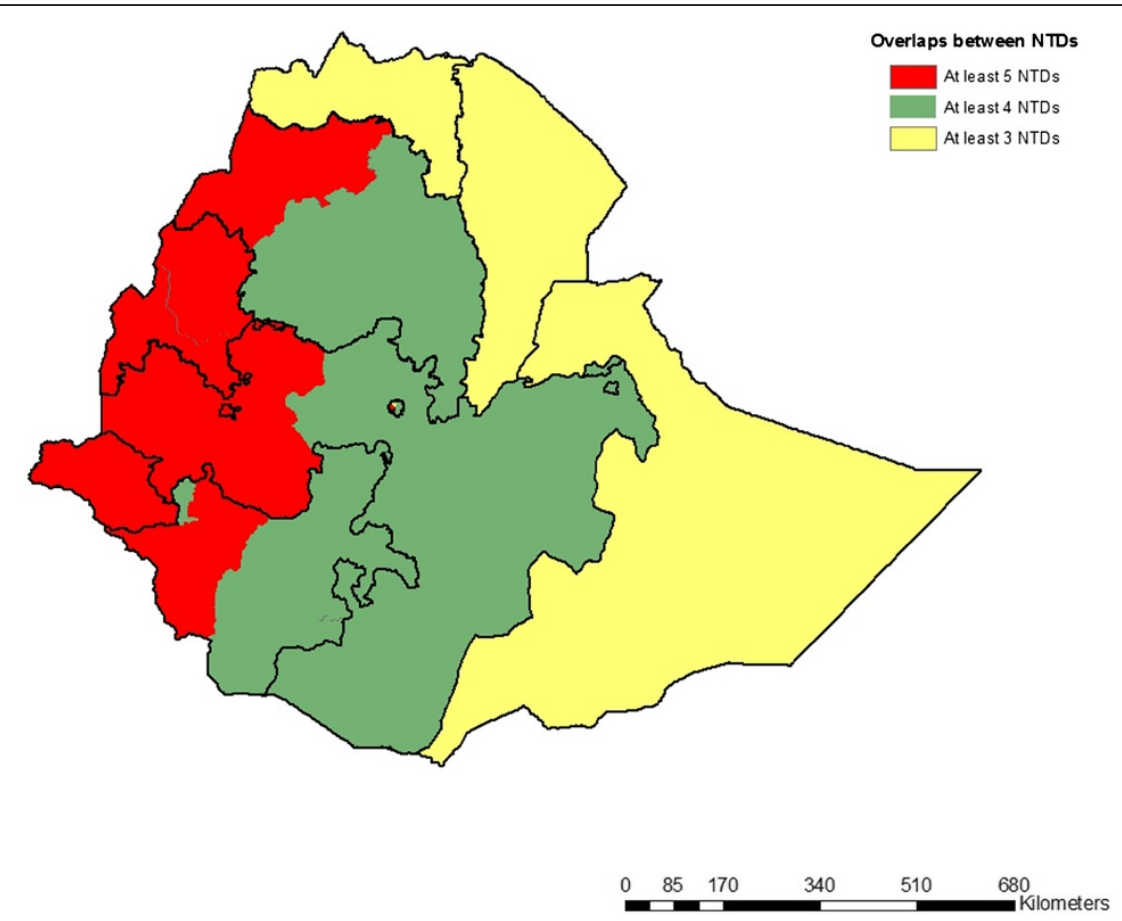

Figure 4 Overlap between five common NTDs (soil-transmitted helminth infections; lymphatic filariasis; schistosomiasis; trachoma and onchocerciasis) in Ethiopia as reported by health providers and maps. 
sustainability of programs by sharing resources with better resourced control programs such as HIV/AIDS, tuberculosis and malaria [99]. In Ethiopia the control of NTDs is coordinated by a focal person in the Federal Ministry of Health, and the existence of more than 38,000 trained Health Extension Workers (female salaried health workers) offers great opportunities for integrated NTD control. Two health extension workers are located in each kebele (the lowest administrative unit, consisting of approximately 1000 households). Possible areas of integration might include MDA, health education and hygiene promotion.

Health education is the principal component of most of the control and elimination programs. The target audiences of messages concerning NTDs are similar people, therefore identification of standard messages and production of materials which address multiple NTDs should be considered to harmonize the key NTD messages. Qualitative assessments and socio-cultural studies of knowledge, attitude and practice of endemic communities with respect to NTDs must be utilized in the development of key educational messages.

The other important area for integration is monitoring and evaluation of control and elimination activities. The current Health Management Information System (HMIS) in Ethiopia captures only a few of the NTDs, and unless this is rectified so that routine data on NTDs are collected via the health system, costly and inefficient surveys will be necessary to monitor NTD programs. Data collected via the HMIS could in the future benefit district offices as they monitor their own activities and make decisions at local level. It is anticipated that the National Master Plan for Integrated Control of NTDs 2012-2015 will outline a more precise road map for the implementation of integrated mapping and control of NTDs (Table 4).

\section{Conclusion}

Most NTDs are highly prevalent in Ethiopia; resulting in enormous disease burdens compared even with other Sub-Saharan African countries. However, despite these high burdens of diseases, the control of most NTDs in Ethiopia is in its infancy, and mostly underfinanced.

The key to control of NTDs lies in understanding the geographical distribution of disease in a given country. At the time of this review, only a few NTDs have been adequately mapped in Ethiopia. This indicates the need for integrated mapping to better understand the distribution of particular diseases and areas of overlap for treatment and control. Resource mobilization for conducting integrated surveys should be prioritized. Once the mapping is completed and disease distribution is known, cost estimates for the control of common NTDs within Ethiopia will enable resource mobilization and guide donors and partners.

The development of a National Master Plan for Integrated Control of NTDs is a huge step forward. The overarching goal: "to accelerate integrated control of NTDs in Ethiopia so that NTDs won't be public health problems by 2015" will require coordinated efforts among a range of partners. Operational research into an integrated approach for control of NTDs will also be vital. Financing the control of NTDs in Ethiopia will have huge implications not only for Ethiopia but also for the SSA region.

A national coordinating body of NTDs has been established, and several task forces for specific NTDs exist. Mapping of organizations working on NTDs and their disease interests and geographical coverage would benefit better coordination. Although national level coordination is a priority, regional level coordination should also be given emphasis.

National and international best practices in NTD control must guide the establishment and scale up of interventions. Drawing lessons from the successful and integrated programs for CDTI and trachoma control in Ethiopia is important. Strengthening the health system to respond to NTDs is critical; particularly training health providers prior to service and in-service to adequately treat the NTDs. Accessing diagnostic supplies and medicine for treatment are also important.

A three pronged roll-out package consisting of: laying the groundwork; rolling out an integrated program; and establishing effective management has been demonstrated to be effective in other settings [97], and would likely benefit Ethiopia if adopted.

\section{Disease specific recommendations}

- Onchocerciasis: The CDTI strategy for the control of onchocerciasis has been very effective in reducing and, in some cases, halting transmission in known endemic foci as witnessed by APOC evaluation. Currently, the issue of moving from control to elimination of onchocerciasis in Ethiopia and elsewhere is under consideration by APOC and its partners. It will be crucial to conduct a complete independent review of the national control program and use findings to reorient the program and design elimination strategies. In addition to programmatic reviews, the evaluation should consider entomological, epidemiological and parasitological aspects of control interventions. As evidenced by the elimination programs in the Americas, the initiative is very demanding in terms of human, financial and logistical resources. Therefore, efforts must be made to secure full government commitment and approval before commencing to launching such highly demanding elimination projects.

- Trachoma: The current implementation of the full SAFE strategy for trachoma control is limited mainly to the Amhara region and some parts of SNNPR 
Table 4 Summary of WHO recommended control strategies and their status in Ethiopia, 2012

\begin{tabular}{|c|c|c|c|}
\hline Disease & National Target & WHO recommended control strategy & Status in Ethiopia \\
\hline $\begin{array}{l}\text { Soil Transmitted Helminthes } \\
\text { (STH) (Hookworm, Ascariasis } \\
\text { and Trichuriasis) }\end{array}$ & $\begin{array}{l}\text { To reduce morbidity due to STH } \\
\text { to a level where it is no longer of } \\
\text { public health significance. }\end{array}$ & $\begin{array}{l}\text { Annual mass treatment of school age children } \\
\text { and whole communities in high-prevalence } \\
\text { areas }\end{array}$ & $\begin{array}{l}\text { Deworming } 2-5 \text { year old children } \\
\text { every six months nationwide }\end{array}$ \\
\hline Schistosomiasis & $\begin{array}{l}\text { To reduce morbidity due to } \\
\text { schistosomiasis to a level where } \\
\text { it is no longer of public health } \\
\text { significance. }\end{array}$ & $\begin{array}{l}\text { Annual mass treatment of school age children } \\
\text { and whole communities in high-prevalence } \\
\text { areas }\end{array}$ & $\begin{array}{l}\text { No active control program case } \\
\text { management and MDA in few places }\end{array}$ \\
\hline Lymphatic filariasis & $\begin{array}{l}\text { To eliminate LF as a public health } \\
\text { problem by } 2020\end{array}$ & $\begin{array}{l}\text { Annual MDA to treat the entire population } \\
\text { for a (currently undefined) period, to } \\
\text { interrupt transmission }\end{array}$ & $\begin{array}{l}\text { Annual MDA in identified endemic } \\
\text { areas since } 2009\end{array}$ \\
\hline Onchocerciasis & $\begin{array}{l}\text { To eliminate onchocerciasis as a } \\
\text { public health problem by } 2015\end{array}$ & $\begin{array}{l}\text { Vector control through spraying of larvicides } \\
\text { and annual CDTI }\end{array}$ & CDTI since 2000 \\
\hline Podoconiosis & To control podoconiosis in Ethiopia & $\begin{array}{l}\text { Under development; includes community- } \\
\text { based treatment of cases consisting of foot } \\
\text { hygiene, use of shoes, wound care, etc. }\end{array}$ & $\begin{array}{l}\text { Community-based treatment of cases } \\
\text { consisting of foot hygiene, use of } \\
\text { shoes, wound care in few endemic } \\
\text { places }\end{array}$ \\
\hline Trachoma & $\begin{array}{l}\text { To eliminate blinding trachoma } \\
\text { through SAFE strategy by } 2020\end{array}$ & $\begin{array}{l}\text { Surgery, antibiotic therapy, facial cleanliness } \\
\text { and environmental improvement (SAFE) } \\
\text { strategy }\end{array}$ & $\begin{array}{l}\text { Surgery, antibiotic therapy, facial } \\
\text { cleanliness and environmental } \\
\text { improvement (SAFE) strategy }\end{array}$ \\
\hline $\begin{array}{l}\text { Human African } \\
\text { trypanosomiasis }\end{array}$ & Cases were not reported since 1984 & $\begin{array}{l}\text { Case detection and treatment. Vector control } \\
\text { through spraying, traps and targets }\end{array}$ & None \\
\hline Leprosy & Eliminated from Ethiopia & Multidrug therapy & $\begin{array}{l}\text { Multidrug therapy, reduce disability, } \\
\text { early case detection }\end{array}$ \\
\hline Leishmaniasis & To control leishmaniasis in Ethiopia & $\begin{array}{l}\text { Case detection and treatment and personal } \\
\text { protection through use of mosquito nets }\end{array}$ & Case management in endemic areas \\
\hline Dracunculiasis & $\begin{array}{l}\text { Eradication of Guinea worm in } \\
\text { Ethiopia with certification by the } \\
\text { international commission by } 2015\end{array}$ & $\begin{array}{l}\text { Active case detection and containment, } \\
\text { provision of water supply, abate application } \\
\text { and use of cloth and pipe filters }\end{array}$ & $\begin{array}{l}\text { Active case detection and containment, } \\
\text { provision of safe water supply, abate } \\
\text { application and use of cloth and pipe } \\
\text { filters }\end{array}$ \\
\hline Buruli ulcer & No target & Case detection, treatment and surgery & Case management \\
\hline Echinococcosis & No target & $\begin{array}{l}\text { Case detection and treatment, regular } \\
\text { deworming of dogs, providing health } \\
\text { information and inspecting meat. }\end{array}$ & Case management \\
\hline Rabies & No target & $\begin{array}{l}\text { Controlling rabies in both wild and domestic } \\
\text { animals; providing pre-exposure immunization } \\
\text { to humans at occupational risk of contracting } \\
\text { the disease; and on delivering post-exposure } \\
\text { prophylaxis to potentially exposed patients }\end{array}$ & $\begin{array}{l}\text { Post-exposure prophylaxis to potentially } \\
\text { exposed patients. }\end{array}$ \\
\hline Fascioliasis & No target & $\begin{array}{l}\text { Preventive chemotherapy and case detection } \\
\text { and treatment }\end{array}$ & Case management \\
\hline
\end{tabular}

and Oromia. If Ethiopia is poised to achieve the GET2020 targets, the program needs to scale up aggressively to all affected regions and most particularly in Oromia (where there is the 2nd highest burden of disease in the country). In order to clear the huge backlog of trichiasis, special surgical strategies should be designed in collaboration with the respective regional health bureaus and their partners/ donors.

- Dracunculiasis: The Ethiopian Dracunculiasis Eradication Program (EDEP) is working very hard to achieve complete interruption of GWD transmission by 2012. Due to the apparent risk of reintroduction of infection from South Sudan (which is the only neighboring endemic country), the program must stay vigilant along the common borders to detect and contain cases as they occur. Heightening public awareness and publicizing the cash reward system to the whole country (using all available communication channels) should remain top priority for the national program. The National Certification Committee should continue to work closely with the program to ensure proper documentation of program interventions and preparation of a Country Report for the International Certification Commission.

- Leishmaniasis: Ethiopian Cutaneous Leishmaniasis, caused by the species Leishmania aethiopica, is a major health problem in the highlands (1400 - 1900m) of Ethiopia, and the cycle is maintained zoonotically by rock hyraxes. There are no sensitive laboratory-based 
diagnostic tests, and treatments are variably effective. Thus case detection suffers from unavailability of simple and sensitive tests as well as absence of safe and effective treatments. New tools for diagnosis and effective treatments are needed. Epidemiological mapping is currently underway. Mapping the geographical distribution of sandfly vectors ( $P$. longipes and $P$. pedifer) and rock hyraxes (Procavia capensis and Heterohyrax brucei) will complement efforts to map the disease. The integration of cutaneous leishmaniasis into the mapping and control efforts of other NTDs will be a challenge, and caution is needed so as not to undermine leishmaniasis control efforts.

- Visceral leishmaniasis, which largely occurs in the Ethiopian lowlands including the rift valley regions, is co-endemic with malaria. There is no evidence of overlap with onchocerciasis and LF. Co-infection with HIV in north Ethiopia and among specific risk groups (migrant workers and military personnel) is an issue that deserves public health intervention. The treatment of HIV co-infected patients remains a challenge. Effective treatments for achieving initial cure and secondary prophylaxis for prevention of relapses are needed. The availability of rapid diagnostic tests, e.g. rk39 dipsticks, has offered the opportunity for enhanced VL case detection. Nonetheless, treatments for VL remain prohibitively expensive. Attempts to shorten the duration of treatment from the current 4 weeks (antimony-based treatments) or 17 days (paromomycin and antimony combinations) to less than 10 days need to be strengthened and enhanced. While VL transmission areas are fairly well known, the potential of the disease to spread to new localities needs to be acknowledged. Mapping the geographical distribution of sandfly vectors (mainly Phelebotomus martini, and $P$. orientalis) must be enhanced. New tools for detection of asymptomatic infections in humans are needed; and defining their role in transmission is a critical step towards designing an effective control strategy.

- Lymphatic filariasis: The recently started mapping efforts and MDA-based interventions must be enhanced and laid on a solid programmatic foundation possibly integrated with the onchocerciasis control programme. The MDA-programs must be complemented with efforts to monitor effectiveness of the interventions as well as the efficacy of treatments, i.e., ivermectin and albendazole. For this to happen, it is necessary to establish sentinel epidemiological sites for baseline assessment, monitoring impact of interventions and efficacy of drugs. A close supervision of the programs in place is a vital step for ensuring success.
- Schistosomiasis: Mapping the distribution of schistosomiasis is an important first step to establishing a national schistosomiasis control program. While the mapping is undertaken, the Ministry of Health must use existing evidence to initiate appropriate treatment and control activities.

- Podoconiosis: Nationwide mapping integrated with that of LF is the first priority, followed by development of pre- and in-service training modules for school teachers, agricultural extension workers, and all levels of health professionals, in conjunction with the Ministries of Education and Health. Close monitoring and evaluation of community based delivery of prevention and care through inclusion of key indicators into the HMIS will also be important.

- Leprosy: New cases of leprosy are reported at the same rate as decades ago although Ethiopia has reportedly met the elimination target. The difference now is that the country has a much reduced control intensity relying on general health care providers with fewer active leprosy experts linked to control than decades ago. The case of leprosy illustrates the challenges of integrating disease control with adequate vigilance to maintain rather rare excellence accumulated through years of control while adapting to changes in priorities dictated by epidemiologic, socio-economic and development realities.

\section{Competing interests}

The authors declare that they have no competing interests.

\section{Authors' contributions}

Conceived and designed the review: KD, GD, KD, GD drafted the initial review. KM, TG, AH, AL, AA contributed disease specific information and review. All authors read and approved the final manuscript.

\section{Acknowledgements}

We are grateful to the authors of the articles presented here, which is the basis of the review.

\section{Funding}

KD is supported by TOMS Shoes for preparatory work of podoconiosis mapping. GD is supported by the Wellcome Trust (079791) for podoconiosis research.

\section{Author details}

${ }^{1}$ Brighton and Sussex Medical School, Falmer, Brighton, United Kingdom. ${ }^{2}$ Federal Ministry of Health Ethiopia, Addis Ababa, Ethiopia. ${ }^{3}$ International Trachoma Initiative, The Task Force for Global Health, Addis Ababa, Ethiopia. ${ }^{4}$ Faculty of Medicine, Addis Ababa University, Addis Ababa, Ethiopia. ${ }^{5}$ School of Public Health, Addis Ababa University, Addis Ababa, Ethiopia. ${ }^{6}$ Armauer Hansen Research Institute/ALERT, Addis Ababa, Ethiopia.

Received: 4 September 2012 Accepted: 1 October 2012

Published: 24 October 2012

\section{References}

1. WHO: Working to overcome the global impact of neglected tropical diseases: first WHO report on neglected tropical diseases. World Health Organization: 2010. http://whqlibdoc.who.int/publications/2010/9789241564090_eng.pdf. 2. Hotez PJ, Molyneux DH, Fenwick A, Kumaresan J, Sachs SE, Sachs JD, Savioli L: Control of neglected tropical diseases. N Engl J Med 2007, 357:1018-1027. 
3. WHO: Neglected tropical diseases, hidden successes, emerging opportunities. Department of Control of Neglected Tropical Diseases. Geneva: World Health Organization; 2006. http://whqlibdoc.who.int/hq/2006/ WHO_CDS_NTD_2006.2_eng.pdf.

4. Liese B, Rosenberg M, Schratz A: Programmes, partnerships, and governance for elimination and control of neglected tropical diseases. Lancet 2010, 375(9708):67-76

5. Hotez PJ, Fenwick A, Savioli L, Molyneux DH: Rescuing the "bottom billion" through neglected tropical disease control. Lancet 2009, 373:1570-1576.

6. Addiss DG: Global elimination of lymphatic filariasis: addressing the public health problem. PLOS Negl Trop Dis 2010, 4(6):e741.

7. Taylor MJ, Hoerauf A, Bockarie M: Lymphatic filariasis and onchocerciasis. Lancet 2010, 376(9747):1175-1185.

8. Molyneux DH, Malecela MN: Neglected tropical diseases and the millennium development goals: why the "other diseases" matter: reality versus rhetoric. Parasit Vectors 2011, 13(4):234.

9. Litt E, Baker MD, Molyneux D: Neglected tropical diseases and mental health: a perspective on comorbidity. Trends Parasitol 2012, 28(5):195-201.

10. Hotez PJ, Kamath A: Neglected tropical diseases in sub-saharan Africa: review of their prevalence, distribution, and disease burden. PLOS Negl Trop Dis 2009, 3(8):e412.

11. Pullan $L R$, Brooker $S J$ : The global limits and population at risk of soiltransmitted helminth infections in 2010. Parasit Vectors 2012, 5(81):

12. Tadesse Z, Hailemariam A, Kolaczinski JH: Potential for integrated control of neglected tropical diseases in Ethiopia. Trans R Soc Trop Med Hyg 2008, 2008(102):213-214.

13. Fekadu D, Petros B, Kebede A: Hookworm species distribution among school children in Asendabo Town, Jimma Zone, Southwest Ethiopia. Ethiop J Health Sci 2008, 18(2):53-56.

14. Demissie F, Kebede A, Shimels T, Beyene P: Assessment of public health implication of malaria-geohelminth co-infection with an emphasis on hookworm-malaria anemia among suspected malaria patients in asendabo, southwest Ethiopia. Ethiop Med J 2009, 47(2):153-158.

15. Erosie L, Merid Y, Ashiko A, Ayine M, Balihu A, Muzeyin S, Teklemariam S, Sorsa S: Prevalence of Hookworm infection and hemoglobin status among rural elementary school children in Southern Ethiopia. Ethiop J Health Dev 2002, 16(1):113-115.

16. Wondimagegnehu T, Woldemichael T, Assefa T: Hookworm infection among the Melka Sedi banana plantation residents, middle Awash Valley, Ethiopia. Ethiop Med J 1992, 30(3):129-134.

17. Yami A, Mamo Y, Kebede S: Prevalence and Predictors of Intestinal Helminthiasis Among School Children in Jimma Zone; A Cross-Sectional Study Ethiop. J Health Sci 2011, 21(3):167-174.

18. Alemu A, Atnafu A, Addis Z, Shiferaw Y, Teklu T, Mathewos B, Birhan W, Gebretsadik S, Gelaw B: Soil transmitted helminths and schistosoma mansoni infections among school children in Zarima town, northwest Ethiopia. BMC Infect Dis 2011, 9(11):189.

19. Steinmann P, Keiser J, Bos R, Tanner M, Utzinger J: Schistosomiasis and water resources development: systematic review, meta-analysis, and estimates of people at risk. Lancet Infect Dis 2006, 6(7):411-425.

20. Shiferaw W, Kebede T, Graves PM, Golasa L, Gebre T, Mosher AW, Tadesse A Sime H, Lambiyo T, Panicker KN, et al: Lymphatic filariasis in western Ethiopia with special emphasis on prevalence of Wuchereria bancrofti antigenaemia in and around onchocerciasis endemic areas. Trans $R$ Soc Trop Med Hyg 2012, 106(2):117-127.

21. Davey G, Tekola F, Newport MJ: Podoconiosis: non-infectious geochemical elephantiasis. Trans R Soc Trop Med Hyg 2007, 101(12):1175-1180.

22. Tekola F, HaileMariam D, Davey G: Economic costs of endemic non-filarial elephantiasis in Wolaita Zone, Ethiopia. Trop Med Int Health 2006, 11(7):1136-1144.

23. WHO: Global health atlas. Global Alliance for the Elimination of Blinding Trachoma database; 2008. http://www.who.int/globalatlas.

24. WHO: Human African trypanosomiasis (sleeping sickness): epidemiological update. Wkly Epidemiol Rec 2006, 81(8):69-80.

25. WHO: Global leprosy situation, beginning of 2008. Wkly Epidemiol Rec 2008, 83(33):293-300.

26. Alvar J, Vélez ID, Bern C, Herrero M, Desjeux P, Cano J, Jannin J, den Boer M: the WHO Leishmaniasis Control Team. Leishmaniasis Worldwide and Global Estimates of Its Incidence. PLoS One 2012, 7(5):e35671.

27. WHO: Dracunculiasis eradication - global surveillance summary,2011. Wkly Epidemiol Rec 2012, 87(19):177-188.
28. Haileamlak A, Girma C, Bekele A: Buruli Ulcer: The first reported case from Ethiopia. Ethiop J Health Sci 2006, 19(3):193-197.

29. Erko B, Ye-Ebiyo Y, Seyoum A, Desta H, Teklehaymanot A: An overview of neglected tropical diseases in Ethiopia. Ethiopian: Journal of Biological Sciences; 2007

30. Kebede N, Mitiku A, Tilahun G: Retrospective survey of human hydatidosis in Bahir Dar, north-western Ethiopia. East Mediterr Health J 2010, 16(9):937-941.

31. Fekadu M: Human rabies surveillance and control in Ethiopia. In Proceedings of the Southern and Eastern African Rabies Group Meeting Nairobi, Kenya; 1997.

32. Bogel $\mathrm{K}, \mathrm{MoTs}$ (hwiller $\mathrm{E}$ : Incidence of rabies and post exposure treatment in developing countries. Bull World Health Organ 1986, 64(6):883-887.

33. Jemaneh $\mathrm{L}$ : The epidemiology of schistosomiasis mansoni and soiltransmitted helminths in elementary school children from the South Gondar Zone of the Amhara National Regional State, Ethiopia. Ethiop Med J 2000, 38(2):105-118.

34. Erko B, Medhin G: Human helminthiasis in Wondo Genet, southern Ethiopia, with emphasis on geohelminthiasis. Ethiop Med J 2003, 41(4):333-344

35. Birrie H, Tedla S, Tilahun G, Kloos H, Eshete H: Schistosomiasis and its distribution in Ethiopia and Eritrea. In Schistosomiasis in Ethiopia and Eritrea. Edited by Birrie H, Tedla S, Jemaneh L.: Institute of Pathobiology: Addis Ababa University Printing Press; 1998:29-86.

36. WHO: The control of schistosomiasis. Report of WHO Expert Committee. Geneva: WHO; 1985.

37. Kloos H, Lo CT, Birrie H, Ayele T, Tedla S, Tsegay F: Schistosomiasis in Ethiopia. Soc Sci Med 1988, 26(8):803-827.

38. Aseffa A: Armauer Hansen Research Institute/ALERT- Consultative Meeting on The Control of Leishmaniasis in the African Region WHO/AFRO Addis Ababa; 2010.

39. Ashford RW, Bray MA, Hutchinson MP, Bray RS: The epidemiology of cutaneous leishmaniasis in Ethiopia. Trans R Soc Trop Med Hyg 1973, 67(4):568-602

40. Bryceson AD: Diffuse cutaneous leishmaniasis in Ethiopia. II. Treatment. Trans R Soc Trop Med Hyg 1970, 64:369-379.

41. Mengistu G, Laskay T, Gemetchu T, Humber D, Ersamo M, Evans D, Teferedegn H, Phelouzat MA, Frommel D: Cutaneous leishmaniasis in south-western Ethiopia: Ocholo revisited. Trans R Soc Trop Med Hyg 1992, 86(2):149-153

42. Negera E, Gadisa E, Yamuah L, Engers H, Hussein J, Kuru T, Hailu A, Gedamu $L$, Aseffa A: Outbreak of cutaneous leishmaniasis in Silti woreda, Ethiopia: risk factor assessment and causative agent identification. Trans $R$ SoC Trop Med Hyg 2008, 102(9):883-890.

43. Herrero M, Orfanos G, Argaw D, Mulugeta A, Aparicio P, et al: Natural History of a Visceral Leishmaniasis Outbreak in Highland Ethiopia. Am J Trop Med Hyg 2009, 81(3):373-377.

44. Bashaye S, Nombela N, Argaw D, Mulugeta A, Herrero M: Risk factors for visceral leishmaniasis in a new epidemic site in Amhara Region, Ethiopia. Am J Trop Med Hyg 2009, 81(1):34-39.

45. Negera E, Gadissa E, Yamuah L, Engers H, Hussein J: Outbreak of cutaneous leishmaniasis in Silti woreda, Ethiopia: risk factor assessment and causative agent identification. Trans $R$ Soc Trop Med Hyg 2008, 102(9):883-890.

46. Alvar J, Aparicio P, Aseffa A, Den Boer M, Cañavate C, et al: The Relationship between Leishmaniasis and AIDS: the Second 10 Years. Clin Microb Rev 2008, 21(2):334-359.

47. ter Horst R, Collin SM, Ritmeijer K, Bogale A, Davidson RN: Concordant HIV Infection and Visceral Leishmaniasis in Ethiopia: The Influence of Antiretroviral Treatment and Other Factors on Outcome. Clin Infect Dis 2008, 46:1702-1709.

48. Prasittisuk C: Vector-control synergies, between 'roll back malaria' and the Global Programme to eliminate lymphatic filariasis, in southeast Asia. Ann Trop Med Parasitol 2002, 96(Suppl 2):33-37.

49. Bogh C, Pedersen EM, Mukoko DA, Ouma JH: Permethrin-impregnated bed net effects on resting and feeding behavior of lymphatic filariasis vector mosquitoes in Kenya. Med Vet Entomol 1998, 12:52-59.

50. Davey G: Recent advances in podoconiosis. Ann Trop Med Parasitol 2009, 103(5):377-382.

51. Kloos H, Kello AB, Addus A: Podoconiosis (endemic non-filarial elephantiasis) in two resettlement schemes in western Ethiopia. Trop Doct 1992, 22:109-112. 
52. Yakob B, Deribe K, Davey G: High levels of misconceptions and stigma in a community highly endemic for podoconiosis in southern Ethiopia. Trans R Soc Trop Med Hyg 2008, 102(5):439-444.

53. Burton MJ, Frick KD, Bailey RL, Bowman RJC: Azithromycin for the treatment and control of trachoma. Expert Opin Pharmacother 2002, 3(2):113-120.

54. FMOH: National Survey on Blindness, Low Vision and Trachoma in Ethiopia. Addis Ababa, Ethiopia: Federal Ministry of Health of Ethiopia; 2006.

55. FMOH: Federal Ministry of Health of Ethiopia. National Five Year Strategic Plan for eye care in Ethiopia (2006-2010). Addis Ababa: Diseases Prevention and Control Department Federal Ministry of Health; 2006.

56. Boatin BA, Richards FO J: Control of Onchocerciasis. In Advance in Parsitology Control of Human Parasitic Diseases. Edited by Molyneux DH. London: Elsevier Ltd; 2007.

57. Zein ZA, Kloos H: The ecology of Health and disease in Ethiopia. Addis Ababa: Ministry of Health; 1988:1-308.

58. Zein AZ: An appraisal of the epidemiologic situation of onchocerciasis in Ethiopia. Parassitologia 1990, 32(2):237-244.

59. Yirga D, Deribe K, Woldemichael K, Wondafrash M, Kassahun W: Factors associated with compliance with community directed treatment with ivermectin for onchocerciasis control in Southwestern Ethiopia. Parasites \& Vectors 2010, 3(48): .

60. WHO: African Programme for Onchocerciasis Control (APOC) Country profile. Ethiopia: World Health Organization; 2012. http://www.who.int/apoc/ countries/eth/en/index.html.

61. Gundersen SG, Schmitt-Lechner A, Bjorvatn B: Onchocerciasis in the Blue Nile Valley of western Ethiopia. Trans R Soc Trop Med Hyg 1988, 82(1):122-127.

62. The Carter Center: 2010 Program review for the Lions-Carter Center SightFirst River Blindness Programs, Cameron, Ethiopia, Nigeria, OEPA, SUDAN and Uganda. 28 February-2 March 2011. Atlanta, GA: The Carter Center; 2011.

63. WHO: Leprosy update. Wkly Epidemiol Rec 2011, 86(36):389-400.

64. Ministry of Health: Tuberculosis and Leprosy control of Ethiopia. Tenth Annual Review Meeting, 18 to 20 September; 2002.

65. FMoH: Presentation at the National Leprosy Workshop at AHRl; 2012.

66. Tefera G, Yimer E, Geyid A: Endemic existence of rabies in Ethiopia. Ethiop Med J 2002, 40(2):163-170.

67. Fekadu M: Atypical rabies in dogs in Ethiopia. Ethiop Med J 1972, 10(3):79-86.

68. WHO: World survey of Rabies for the year 1998 No 34(RABNET). WHO Department of Communicable Disease Surveillance and Response WHO/CDS/ CSR/APH/99.6, 1998; 2000. http://whqlibdoc.who.int/hq/1999/ WHO_CDS_CSR_APH_99.6.pdf.

69. Deressa A, Ali A, Beyene M, Newaye Selassie B, Yimer E, Hussen K: The status of rabies in Ethiopia: a retrospective record review. Ethiop $J$ Health Dev 2010, 24(2):127-132.

70. Yimer E, Newayeselassie B, Teferra G, Mekonnen Y, Bogale Y, Zewde B, Beyene $M$, Bekele $A$ : Situation of rabies in Ethiopia: a retrospective study 1990-2000. Ethiop J Health Dev 2002, 16(1):105-112.

71. Cairncross S, Muller R, Zagaria N: Dracunculiasis (Guinea worm disease) and the eradication initiative. Clin Microbiol 2002, 15:223-246.

72. Ruiz-Tiben E, Hopkins DR: Dracunculiasis (Guinea Worm Disease) Eradication. In Advance in Parsitology Control of Human Parasitic Diseases. Edited by Molyneux DH. London: Elsevier Ltd; 2007.

73. Smith GS, Blum D, Huttly SR, Okeke N, Kirkwood BR, Feachem RG: Disability from dracunculiasis: effect on mobility. Ann Trop Med Parasitol 1989, 83:151-158.

74. ten Eyck DR: Report of an outbreak of dracunculiasis in Ethiopia. Ethiop Med J 1971, 9(3):149-152.

75. Berhane Y, Hail Mariam D, Kloos H: The Ecology of Health and disease in Ethiopia. Addis Ababa: Shama books; 2006:1-308.

76. WHO: World Health organization. Dracunculiasis eradication - global surveillance summary, 2011. Wkly Epidemiol Rec 2012, 87(19):177-188.

77. WHO: World Health organization. Human African trypanosomiasis (sleeping sickness): epidemiological update. Wkly Epidemiol Rec 2006, 81(8):69-80.

78. Central Statistical Agency [Ethiopia], ICF International: Ethiopia Demographic and Health Survey 2011. Addis Ababa, Ethiopia and Calverton, Maryland, USA: Central Statistical Agency and ICF International; 2012.

79. Kolaczinski JH, Kabatereine NB, Onapa AW, Ndyomugyenyi R, Kakembo AS, Brooker S: Neglected tropical diseases in Uganda: the prospect and challenge of integrated control. Trends Parasitol 2007, 23(10):485-493.
80. Sikorski C, Ashine M, Zeleke Z, Davey G: Effectiveness of a simple lymphoedema treatment regimen in podoconiosis management in southern Ethiopia: one year follow-up. PLoS Neg/ Trop Dis 2010, 4(11):e902.

81. Davey G, Burridge E: Community-based control of a neglected tropical disease: the mossy foot treatment and prevention association. PLOS Negl Trop Dis 2009, 3(5):e424.

82. Negash S: Enhanced Outreach Strategy/ Targeted Supplementary Feeding for Child Survival in Ethiopia (EOS/ TSF). Field Exchange 2011, 40(8):7-10.

83. WHO: Schistosomiasis: population requiring preventive chemotherapy and number of people treated in 2010. Wkly Epidemiol Rec 2012, 87(4):37-44.

84. Brooker S, Hotez PJ, Bundy DA: The global atlas of helminth infection: mapping the way forward in neglected tropical disease control. PLOS Negl Trop Dis 2010, 4(7):e779.

85. Baker MC, Mathieu E, Fleming FM, Deming M, King JD, Garba A, Koroma JB, Bockarie M, Kabore A, Sankara DP, et al: Mapping, monitoring, and surveillance of neglected tropical diseases: towards a policy framework. Lancet 2010, 16(375):9710.

86. Price EW: Endemic elephantiasis of the lower legs in Ethiopia an epidemiological survey. Ethiop Med J 1974, 12(2):77-90.

87. Kabatereine NB, Standley CJ, Sousa-Fiqueiredo JC, Fleming FM, Stothard JR, Talisuna A, Fenwick A: Integrated prevalence mapping of schistosomiasis, soil-transmitted helminthiasis and malaria in lakeside and island communities in Lake Victoria. Uganda. Parasit Vectors 2011, 13(4):232.

88. Dorkenoo AM, Bronzan RN, Ayena KD, Anthony G, Agbo YM, Sognikin KS, Dogbe KS, Amza A, Sodahlon Y, Mathieu E: Nationwide integrated mapping of three neglected tropical diseases in Togo: countrywide implementation of a novel approach. Trop Med Int Health 2012, 17(7):896-903.

89. Kolaczinski JH, Hanson K, Robinson E, Picon D, Sabasio A, Mpakateni M, Lado M, Moore S, Petty N, Brooker S: Integrated surveys of neglected tropical diseases in southern Sudan: how much do they cost and can they be refined? PLoS Negl Trop Dis 2010, 4(7):e745.

90. Brooker $\mathrm{S}$, Utzinger J: Integrated disease mapping in a polyparasitic world. Geospat Health 2007, 1(2):141-146.

91. Emerson PM, Ngondi J, Biru E, Graves PM, Ejigsemahu Y, Gebre T, Endeshaw $T$, Genet A, Mosher AW, Zerihun M, et al: Integrating an NTD with one of "The big three": combined malaria and trachoma survey in Amhara Region of Ethiopia. PLoS Negl Trop Dis 2008, 2(3):e197.

92. Pullan RL, Gething PW, Smith JL, Mwandawiro CS, Sturrock HJ, Gitonga CW, Hay SI, Brooker S: Spatial modelling of soil-transmitted helminth infections in Kenya: a disease control planning tool. PLOS Negl Trop Dis 2011, 5(2):e958.

93. Molyneux DH, Hotez PJ, Fenwick A: 'Rapid-impact interventions': how a policy of integrated control for Africa's neglected tropical diseases could benefit the poor. PLoS Med 2005, 2:e336.

94. Hotez PJ, Molyneux DH, Fenwick A, Ottesen E, Ehrlich Sachs S, Sachs JD: Incorporating a rapid-impact package for neglected tropical diseases with programs for HIV/AIDS, tuberculosis, and malaria.2006: 3, e102. PLOS Med 2006, 3:e102.

95. Brady MA, Hooper PJ, Ottesen EA: Projected benefits from integrating NTD programs in sub-Saharan Africa. Trends Parasitol 2006, 22:285-291.

96. Hanson C, Weaver A, Zoerhoff KL, Kabore A, Linehan M, Doherty A, Engels $D$, Savioli L, Ottesen EA: Integrated implementation of programs targeting neglected tropical diseases through preventive chemotherapy: identifying best practices to roll out programs at national scale. Am J Trop Med Hyg 2012, 86(3):508-513.

97. Grépin KA, Reich MR: Conceptualizing integration: a framework for analysis applied to neglected tropical disease control partnerships. PLoS Negl Trop Dis 2008, 2(4):e174.

98. Hotez PJ, Mistry N, Rubinstein J, Sachs JD: Integrating neglected tropical diseases into AIDS, tuberculosis, and malaria control. N Engl J Med 2011, 384(22):2086-2089.

99. Gyapong JO, Gyapong M, Yellu N, Anakwah K, Amofah G, Bockarie M, Adje $S$ : Integration of control of neglected tropical diseases into health-care systems: challenges and opportunities. Lancet 2010, 375(9709):160-165.

doi:10.1186/1756-3305-5-240

Cite this article as: Deribe et al:: The burden of neglected tropical diseases in Ethiopia, and opportunities for integrated control and elimination. Parasites \& Vectors 2012 5:240 